\title{
Evaluation of the practices of using paracetamol among parents in treating their children in Penang, Malaysia
}

\author{
Ee Theng Yeoh ${ }^{1}$, Angel Wei Ling Goh², Chee Ping Chong ${ }^{2 *}$ \\ ${ }^{1}$ Department of Pharmacy, Gleneagles Hospital Penang, George Town, Malaysia. \\ ${ }^{2}$ Discipline of Clinical Pharmacy, School of Pharmaceutical Sciences, Universiti Sains Malaysia USM, Minden, Malaysia.
}

\begin{tabular}{l}
\hline ARTICLE INFO \\
\hline Received on: $19 / 04 / 2021$ \\
Accepted on: 09/08/2021 \\
Available Online: 05/01/2022
\end{tabular}

Key words:

Paracetamol, parents, children, practices, Penang, Malaysia.

\begin{abstract}
Paracetamol is commonly used to treat fever in young children. This study aims to evaluate the practices of using paracetamol among parents from Penang, Malaysia, in treating their children. Data were collected from a total of 93 parents from Penang, Malaysia, in August 2019. Most parents were between 26 and 40 years old (67.7\%) and had at least two children $(74.2 \%)$. About $54.2 \%$ of parents had children aged between 4 and 9 years. The majority of parents $(87.1 \%)$ had used paracetamol to treat their children with $77.9 \%$ of them using it for fever. Approximately half of the parents $(53.1 \%)$ used paracetamol when their children's body temperatures were between $37.5^{\circ} \mathrm{C}$ and $38.0^{\circ} \mathrm{C}$. Syrup $(66.1 \%)$ and chewable tablets $(20.2 \%)$ were the most popular forms of paracetamol used to treat children. The parents mostly use paracetamol every 6 hours $(45.7 \%)$ and 4 hours $(38.3 \%)$. Among the 1-3-year-old children who used paracetamol syrup, $37.5 \%$ of them have exceeded recommended total daily dose. Conversely, $64.7 \%$ of the children aged 10-12 years who consumed paracetamol syrup were found to have below the recommended total daily dose. In conclusion, the practices of using paracetamol among the parents need to be improved to ensure better treatment outcomes for the children.
\end{abstract}

\section{INTRODUCTION}

Paracetamol or acetaminophen is a nonprescription medicine, which is easily accessible over the counter (OTC). It is most widely used as an analgesic or antipyretic for the treatment of many conditions such as headache, muscle ache, and arthritis (Chong et al., 2017). Indeed, paracetamol is used frequently in many countries, and the use is growing in children and infants (Eyers et al., 2012; Lundgren et al., 2017). The recommended dose of paracetamol for children is $15 \mathrm{mg} / \mathrm{kg}$ every 4 to 6 hours with the maximum total dose up to $60 \mathrm{mg} / \mathrm{kg}$ per 24 hours (Bennett, 2013). When given in the right dose, paracetamol is safe to be used. However, when paracetamol is given at too high a dose or taken too frequently, it may result in paracetamol poisoning. There are different types of ingestion causing paracetamol

\footnotetext{
*Corresponding Author

Chee Ping Chong, Discipline of Clinical Pharmacy, School of Pharmaceutical Sciences, Universiti Sains Malaysia USM, Malaysia. E-mail: jjueping@gmail.com
}

poisoning, including acute single ingestion and staggered dose ingestion. An acute single ingestion is an overdose of paracetamol of more than $60 \mathrm{mg} / \mathrm{kg}$ taken at a single defined time point. Meanwhile, a staggering poisoning occurs when the two or more supratherapeutic doses are ingested over the time interval of more than 8 hours, causing a cumulative paracetamol dose of more than $60 \mathrm{mg} / \mathrm{kg}$ (Craig et al., 2012).

Paracetamol is reported to be the most common pharmaceutical agent involved in overdose particularly in children below 6 years old. There is a significant risk of paracetamol overdose in infants and children due to the varying dosing schedules and the various formulations available with different strengths (Choudhury et al., 2011; Obu et al., 2012). The paracetamol dosing in children is weight-based (Lenney, 2012). Therefore, if the child's weight is wrongly measured or estimated, it can lead to inappropriate medication dosing. There is also another method of paracetamol dosing in children which is based on age. Nevertheless, age-based dosing is less accurate in overweight or underweight children. This is because it disregards the large variation in body weight within the age groups and thus 
can potentially cause inappropriate dosing in children. A study showed that overweight children were given one-third to one-half of recommended therapeutic paracetamol dose using age-based dosing (Eyers et al., 2012).

Fever is the most common sign and chief complaint in childhood illnesses; thus, paracetamol is given regularly by numerous parents internationally to lower the body temperature (Eyers et al., 2012; Lundgren et al., 2017). In recent years, the fever phobia phenomenon has been significantly recognized among parents who consider fever as a health threat to their children instead of understanding that fever is an important physiologic response and an infection-fighting mechanism (Martino and Chiarugi, 2015; Villarejo-Rodríguez and RodríguezMartín, 2019). A study in Turkey showed that the fever phobia phenomenon was associated with an increase in self-medication practices (Gunduz et al., 2016). Self-medications have resulted in inappropriate use and overconsumption of antipyretics, commonly including paracetamol (Tesfamariam et al., 2016). Consumers may take the efficacy and safety of paracetamol for granted since it is an easily accessible OTC medicine (Tesfamariam et al., 2016). Improper self-medication may lead to paracetamol poisoning. In Australia, there was a high prevalence of paracetamol poisoning which caused hospital admission (Cairns et al., 2019). Meanwhile, cases of repeated paracetamol overdoses in children were also reported in Malaysia (Chiew et al., 2018).

Lack of health literacy is the main reason for poor knowledge and potential unsafe use of paracetamol products (Shone et al., 2011). Besides, the common practices among Malaysians on self-medication without consultation from healthcare providers could increase the risk of misuse and overconsumption of paracetamol (Almasdy and Sharrif, 2011). Hence, it is believed that, with the proper product labeling, creative educational interventions and health promotion activities may help to promote the correct use of paracetamol among the consumers (Shone et al., 2011). In conclusion, the lack of knowledge and the presence of conflicting information regarding fever and paracetamol make it one of the most prevalent public health issues encountered by parents of young children overseas based on the literature review. There are limited local studies involving paracetamol use in Malaysian parents to treat their children's fever. This study aims to evaluate the practices of paracetamol use among Malaysian parents in treating their children. Thus, this study will provide baseline data for parents with better insights on the correct use of paracetamol.

\section{METHODS}

This was a cross-sectional quantitative structured interview using a questionnaire as the data collection tool which was developed based on a literature review. The questionnaire was pretested for content validity, face validity, and clarity of the questions and instructions by three experts in pharmacy practice research from the School of Pharmaceutical Sciences, Universiti Sains Malaysia. Further refinement was done after pilot testing with five randomly selected parents in Penang, Malaysia, who were not included in the final data analysis. The final questionnaire consisted of four sections. The first section was demographic information, followed by an evaluation of parents' practices, perception, and knowledge with regard to paracetamol in treating their children, respectively, in the remaining sections. However, this article only presented the practices of paracetamol use by parents in treating their children.

The study population was Malaysian parents who visited two shopping malls (Tesco Extra Sungai Dua and Tesco E-gate) and one primary school in Penang state, Malaysia. This study was conducted from August 1 to August 31, 2019. The sample size was calculated by using the Raosoft ${ }^{\circledR}$ software. A sample size of 73 subjects could generate results with a 5\% margin of error and $95 \%$ confidence interval with $95 \%$ of the response distribution. The $95 \%$ of response distribution was based on a previous study involving Penang consumers which showed that a total of $95 \%$ of consumers had experiences in consuming paracetamol (Chong et al., 2017). Convenient sampling was used in this study. Respondents included in this study were parents who can read and listen to the English language. Both parents must have experience in using paracetamol in treating their children aged 12 or below.

The data collection was performed by the principal investigator (first author). The principal investigator approached parents who visited the two mentioned shopping malls and one school. The study information sheet was verbally explained to the potential respondents by the principal investigator. Informed consent was obtained upon respondents' approval. The parents filled up the designed questionnaire themselves or with the help of the principal investigator. The questions were explained by the principal investigator to the parents when necessary. This study had obtained ethics approval from the Medical Research and Ethics Committee, Ministry of Health Malaysia (approval number: NMRR-18-3051-43986). PASW program for Windows package version 23.0 was used to perform all statistical analyses. Descriptive analysis was used and the result was tabulated.

\section{RESULTS}

\section{Demographic characteristics of the respondents}

A total of 93 parents participated in the study with most parents aged between 26 and 40 years $(67.7 \%)$ and more than half were female $(74.2 \%)$. The highest respondents were Malay (75.3\%). Most parents (74.2\%) had at least two children. Slightly more than half of the parents $(54.2 \%)$ had children aged between 4 and 9 years. Meanwhile, there were only three children aged less than 1 year (Table 1).

\section{General practices of using paracetamol products among parents in treating their children}

The majority of the parents $(87.1 \%)$ had given paracetamol to treat their children. Hospital or clinic (58.4\%) and pharmacy $(34.5 \%)$ were among the common places that parents obtained their paracetamol supply. Effectiveness (69.6\%) was the main factor that prompted parents to purchase paracetamol for their children. The parents mostly treated their children with paracetamol for fever $(77.9 \%)$, whereas a few of them wrongly used paracetamol to treat their children for a runny nose $(4.8 \%)$ and infection (1.0\%). When their children's illness persisted after taking paracetamol, most of the parents $(92.6 \%)$ would consult their doctors and pharmacists. Only a few parents would double the dose $(2.5 \%)$ or give it more frequently $(2.5 \%)$ to their children when the body temperature did not subside. The majority of parents $(79.0 \%)$ would measure their children's body temperature 
Table 1. Demographic characteristics of the respondents.

\begin{tabular}{|c|c|c|c|}
\hline Demographic & $N(\%)$ & Demographic & $N(\%)$ \\
\hline Age (years) & & Employment status & \\
\hline $26-40$ & $63(67.7)$ & Unemployed & $20(21.5)$ \\
\hline $41-60$ & $30(32.3)$ & Private sector & $21(22.6)$ \\
\hline Gender & & Monthly income & \\
\hline Male & $24(25.8)$ & Unemployed & $19(20.4)$ \\
\hline \multirow[t]{2}{*}{ Female } & $69(74.2)$ & $<$ RM 1,000 & $2(2.2)$ \\
\hline & & RM 1,000-2,000 & $16(17.2)$ \\
\hline Ethnicity & & $>\mathrm{RM} 2,000-4,000$ & $24(25.8)$ \\
\hline Malay & $70(75.3)$ & $>\mathrm{RM} 4,000$ & $32(34.4)$ \\
\hline Chinese & $15(16.1)$ & & \\
\hline Indian & $5(5.4)$ & Number of children & \\
\hline \multirow[t]{2}{*}{ Others } & $3(3.2)$ & 1 & $24(25.8)$ \\
\hline & & 2 & $34(36.6)$ \\
\hline Education background & & 3 & $27(29.0)$ \\
\hline No formal education & $1(1.1)$ & $>3$ & $8(8.6)$ \\
\hline Primary school & $6(6.5)$ & & \\
\hline Secondary school & $25(26.9)$ & Age of your child (years) & \\
\hline Diploma & $22(23.7)$ & $<1$ & $3(1.8)$ \\
\hline Degree & $30(32.3)$ & $1-3$ & $40(24.1)$ \\
\hline \multirow[t]{3}{*}{ Postgraduate } & $9(9.7)$ & $4-6$ & $46(27.7)$ \\
\hline & & $7-9$ & $44(26.5)$ \\
\hline & & $10-12$ & $33(19.9)$ \\
\hline
\end{tabular}

before treating their fever with paracetamol. Slightly more than half of the parents $(53.1 \%)$ started using paracetamol when their children's body temperatures were between $37.5^{\circ} \mathrm{C}$ and $38.0^{\circ} \mathrm{C}$. Meanwhile, $46.9 \%$ of parents correctly used paracetamol when their children's fever was $38.5^{\circ} \mathrm{C}$ or more.

More than half $(65.4 \%)$ of the parents would bring along paracetamol when traveling with their children. The majority (96.3\%) of parents kept paracetamol at home. Most (95.0\%) parents read the instructions on the package prior to using paracetamol for their children. For those parents who read the instructions, nearly all parents $(98.7 \%)$ understood and followed the instructions mentioned on the package, respectively. Approximately $82.7 \%$ of parents reported that medical advice regarding paracetamol consumption was given to them when purchasing the paracetamol products. The majority of respondents received medical advice on paracetamol from doctors (45.4\%) and pharmacists $(38.9 \%)$. Meanwhile, a few parents reported getting information about paracetamol from the nurses $(14.8 \%)$, and only one of them $(0.9 \%)$ obtained the information from the Internet. Most parents $(82.7 \%)$ followed the instructions given. When looking at the types of medical advice received by the parents, information about the dosage $(27.1 \%)$, frequency $(26.2 \%)$, and indication $(23.5 \%)$ was mostly given to them. Considering the storage, $57.0 \%$ of parents stored the paracetamol in the fridge, while $31.2 \%$ kept it in a cool dry place. Only $11.8 \%$ of the parents kept the paracetamol out of reach of children (Table 2).

\section{The types of formulation, dosage, and frequency of paracetamol use}

The most popular forms of paracetamol used among the parents to treat their children were syrup (66.1\%) and tablet $(20.2 \%)$. All parents $(100.0 \%)$ purchased less than twelve chewable tablets. The majority of parents $(95.8 \%)$ purchased one bottle of syrup paracetamol. When assessing the type of paracetamol dosage form used, more than half of the parents (59.1\%) used two chewable paracetamol tablets (total dose of $240 \mathrm{mg}$ ) to treat their children. Most parents (86.4\%) used only one tablet of paracetamol each time for their children, whereas, for syrup formulation, most parents $(75.0 \%)$ knew the strengths of paracetamol syrup used either $120 \mathrm{mg} / 5 \mathrm{ml}$ or $250 \mathrm{mg} / 5 \mathrm{ml}$, while one-quarter of parents $(25.0 \%)$ were not aware of the strength of the syrup used to treat their children. Considering parents who used $120 \mathrm{mg} / 5 \mathrm{ml}$ syrup paracetamol, more than half of the parents $(56.7 \%)$ used $5 \mathrm{ml}$ each time of treatment. Meanwhile, for those parents using $250 \mathrm{mg} / 5$ $\mathrm{ml}$ syrup paracetamol, near to two-quarters of the parents $(60.0 \%)$ used $5 \mathrm{ml}$ per time to treat their children. For those parents who were not aware of the syrup paracetamol strength, the majority of parents $(63.2 \%)$ served $5 \mathrm{ml}$ each time to treat their children. For the frequency of paracetamol consumption, most parents used it every 6 hours $(45.7 \%)$ and 4 hours $(38.3 \%)$. All parents $(100 \%)$ used paracetamol to treat their children whenever necessary. The majority of children (98.8\%) took paracetamol after food (Table 3). 
Table 2. General practices of paracetamol products used among parents in treating their children.

\begin{tabular}{|c|c|c|}
\hline No & Survey questions & $N(\%)$ \\
\hline \multirow[t]{3}{*}{1.} & Have you ever treated your child with paracetamol? & \\
\hline & Yes & $81(87.1)$ \\
\hline & No & $12(12.9)$ \\
\hline \multirow[t]{5}{*}{2.} & Where do you obtain paracetamol? (you can choose more than one answer) & \\
\hline & Hospital/clinic & $66(58.4)$ \\
\hline & Pharmacy & $39(34.5)$ \\
\hline & Supermarket & $7(6.2)$ \\
\hline & Sundry shop & $1(0.9)$ \\
\hline \multirow[t]{8}{*}{3.} & What is the main factor that you consider when purchase the paracetamol for your child? (you may choose more than one answer) & \\
\hline & Effectiveness & $71(69.6)$ \\
\hline & Quality & $17(16.7)$ \\
\hline & Dosage form design & $6(5.9)$ \\
\hline & Cost & $3(2.9)$ \\
\hline & Quantity & $2(2.0)$ \\
\hline & Strength & $2(2.0)$ \\
\hline & Others (advise from doctor) & $1(1.0)$ \\
\hline \multirow[t]{7}{*}{4.} & Under what condition do you use paracetamol for your child? (you may choose more than one answer) & \\
\hline & Fever & $81(77.9)$ \\
\hline & Sore throat & $12(11.5)$ \\
\hline & Runny nose & $5(4.8)$ \\
\hline & Toothache & $4(3.8)$ \\
\hline & Infection & $1(1.0)$ \\
\hline & Others (pain) & $1(1.0)$ \\
\hline \multirow[t]{6}{*}{5.} & If your child conditions/symptoms persist after taking paracetamol, what would you do? $(N=81)$ & \\
\hline & Consult the doctor/pharmacist & $75(92.6)$ \\
\hline & Double the dose & $2(2.5)$ \\
\hline & Take it more frequently & $2(2.5)$ \\
\hline & Ignore the condition & $1(1.2)$ \\
\hline & Others (use suppository) & $1(1.2)$ \\
\hline \multirow[t]{3}{*}{6.} & Do you measure your child's body temperature with thermometer before you decide to treat him/her with paracetamol? $(N=81)$ & \\
\hline & Yes & $64(79.0)$ \\
\hline & No & $17(21.0)$ \\
\hline \multirow[t]{6}{*}{7.} & When fever occur in your child, in what body temperature will cause you to use paracetamol for treating your child? $(N=64)$ & \\
\hline & $37.5^{\circ} \mathrm{C}-38^{\circ} \mathrm{C}$ & $34(53.1)$ \\
\hline & $38.5^{\circ} \mathrm{C}-39^{\circ} \mathrm{C}$ & $24(37.5)$ \\
\hline & $39.5^{\circ} \mathrm{C}-40^{\circ} \mathrm{C}$ & $5(7.8)$ \\
\hline & $36.5^{\circ} \mathrm{C}-37^{\circ} \mathrm{C}$ & $1(1.6)$ \\
\hline & $>40^{\circ} \mathrm{C}$ & $0(0.0)$ \\
\hline \multirow[t]{3}{*}{8.} & Do you bring paracetamol along while traveling with your child? $(N=81)$ & \\
\hline & Yes & $53(65.4)$ \\
\hline & No & $28(34.6)$ \\
\hline \multirow[t]{3}{*}{9.} & Do you keep paracetamol in your house for your child? $(N=81)$ & \\
\hline & Yes & $78(96.3)$ \\
\hline & No & $3(3.7)$ \\
\hline \multirow[t]{3}{*}{10.} & Do you read the instructions of the package before use it for your child? $(N=81)$ & \\
\hline & Yes & $77(95.0)$ \\
\hline & No & $4(5.0)$ \\
\hline
\end{tabular}




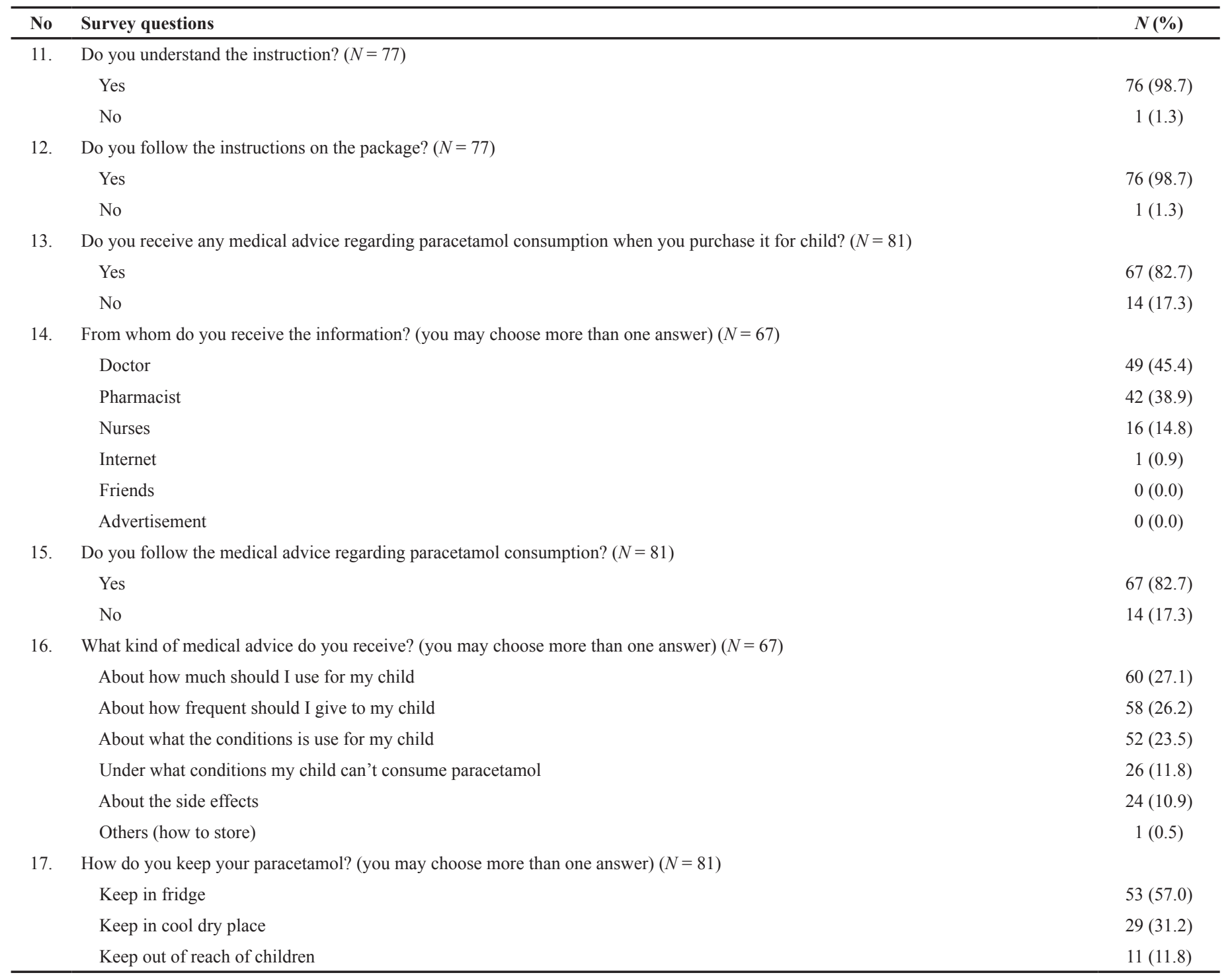

\section{Assessment on the appropriateness of the dose, frequency, and total daily dose given by parents to their children}

The appropriateness of the dose, frequency, and total daily dose given by parents to the children were assessed according to the types of formulation. Most parents used paracetamol syrup to treat children aged between 7 and 9 years $(90.9 \%)$ and 4 and 6 years $(89.1 \%)$, respectively. More than half of parents $(58.1 \%)$ used appropriate doses of syrup paracetamol in children aged 4-6 years. Exceeding three-quarters of parents gave their children the underdose of syrup paracetamol for age groups $7-9$ years $(78.3 \%)$ and $10-12$ years $(76.5 \%)$. In terms of the frequency, more than half of parents gave an appropriate frequency of syrup paracetamol to their children of age groups $1-3$ years $(61.3 \%)$ and $4-6$ years $(61.0 \%)$, respectively. Slightly less than half of the parents gave an appropriate frequency of paracetamol to children aged 7-9 years (47.5\%) and 10-12 years $(47.8 \%)$, respectively. Considering the total daily dose of paracetamol syrup used, $51.6 \%$ of parents provided accurate total daily doses for children between 4 and 6 years old. Less than $40 \%$ of parents gave appropriate total daily dose to their children aged $7-9$ years $(39.1 \%)$ and $10-12$ years $(35.3 \%)$. The trend of underdose of total daily paracetamol doses was more prominent in age groups $7-9$ years $(52.2 \%)$ and $10-12$ years $(64.7 \%)$ (Table 4).

For tablet paracetamol, only four parents (26.7\%) practiced the appropriate dose of paracetamol chewable tablet to treat their children at the age of 10-12 years. None of the parents treated their children with an appropriate dose of tablet paracetamol for the children of age groups 4-6 years and 7-9 years. All parents $(100 \%)$ gave an overdose of paracetamol tablet to children of age group 7-9 years. Around two-thirds of the parents (60.0\%) treated their children with appropriate dosing frequency of paracetamol tablets for the age group 10-12 years, whereas more than half of parents gave their children appropriate total daily doses for the age 
Table 3. The types of formulations, dosage and frequency of paracetamol use.

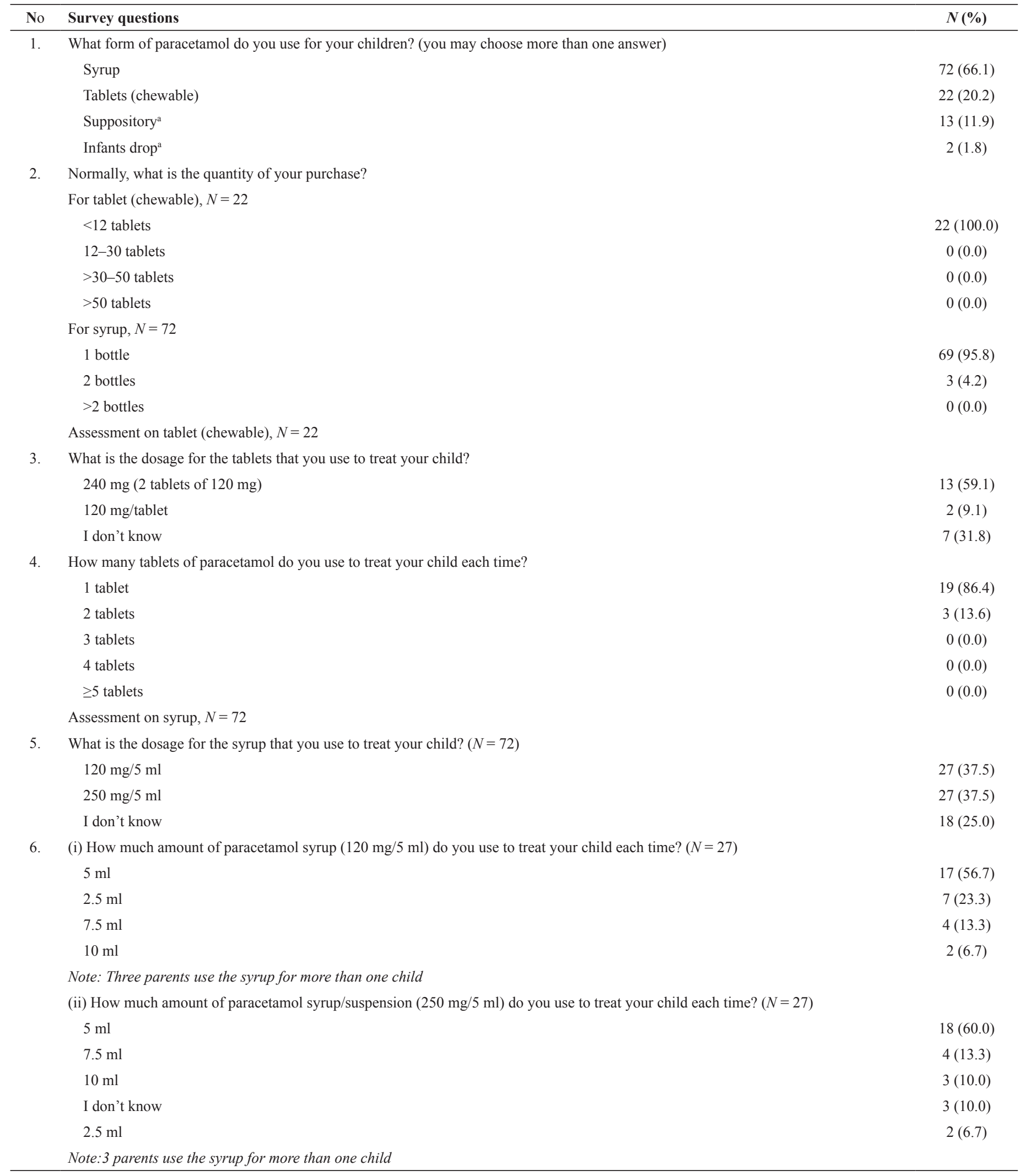




\begin{tabular}{|c|c|c|}
\hline No & Survey questions & $N(\%)$ \\
\hline \multirow[t]{6}{*}{6.} & (iii) How much amount of paracetamol syrup do you use to treat your child each time? (don't know the strength, $N=18$ ) & \\
\hline & $5 \mathrm{ml}$ & $12(63.2)$ \\
\hline & Totally don't know the strength & $4(21.1)$ \\
\hline & $2.5 \mathrm{ml}$ & $2(10.5)$ \\
\hline & $7.5 \mathrm{ml}$ & $1(5.3)$ \\
\hline & Note: 1 parent used the syrup for more than one child & \\
\hline \multirow[t]{5}{*}{7.} & Upon your child consumption of paracetamol tablet/syrup, how frequent do you use for your child? $(N=81)$ & \\
\hline & Every 6 hours & $37(45.7)$ \\
\hline & Every 4 hours & $31(38.3)$ \\
\hline & Every 8 hours & $12(14.8)$ \\
\hline & More than 8 hours & $1(1.2)$ \\
\hline \multirow[t]{5}{*}{8.} & How often do you use paracetamol tablet/syrup for your child? $(N=81)$ & \\
\hline & Whenever the condition appears & $81(100.0)$ \\
\hline & Every month & $0(0.0)$ \\
\hline & Every week & $0(0.0)$ \\
\hline & Everyday & $0(0.0)$ \\
\hline \multirow[t]{3}{*}{9.} & Do your child take paracetamol tablet/syrup before/after meal? $(N=81)$ & \\
\hline & After meal & $80(98.8)$ \\
\hline & Before meal & $1(1.2)$ \\
\hline
\end{tabular}

Question 2-30 involves 81 respondents who ever use paracetamol in treating their children.

${ }^{a}$ The assessment on dosage and frequency of suppository and infant drop were not done due to the small sample size.

groups $7-9$ years $(57.1 \%)$ and $10-12$ years $(60.0 \%)$, respectively (Table 4).

\section{Assessment on the total daily dose given by the parents to their children (syrup and tablet)}

An assessment was done on the total daily dose given by the parents to the children for both syrup and tablet formulations (Table 5). For syrup formulation, the overdose of paracetamol occurred most frequently among children aged 1-3 years $(52.9 \%)$. It was noticed that younger age groups ( $1-3$ years and 4-6 years) had more syrup paracetamol overdose, while higher age groups (7-9 years and 10-12 years) had more syrup paracetamol underdose. The overall total daily dose of syrup paracetamol for both age groups 7-9 years and 10-12 years was seen lesser $($ median $=750 \mathrm{mg}$ ) than the recommended total dose range of 1,050-2,000 and 1,500-3,000 $\mathrm{mg}$, respectively. Meanwhile, for paracetamol tablet formulation, the trend of underdose was seen in all age groups. More than half of the parents $(54.5 \%)$ treated their children at the age of 10-12 years with an underdose of tablet paracetamol. The underdose of paracetamol treatment least happened on children at the age of 4-6 years $(18.2 \%)$. It was observed that the age group 7-9 years was given a lower overall total daily dose (median $=750 \mathrm{mg}$ ) compared to the recommended total dose of 1,050-2,000 mg, while another two age groups were within range (Table 5).

\section{DISCUSSION}

This study revealed that the majority of parents used paracetamol for fever which is consistent with a few studies (Daifallah et al., 2021; Lundgren et al., 2017). Paracetamol is generally not required for the treatment of mild fever under a body temperature of less than $38.5^{\circ} \mathrm{C}$ (Chong et al., 2017). In the present study, only $46.9 \%$ of parents used paracetamol correctly for their children at body temperatures of $38.5^{\circ} \mathrm{C}$ or more. Another study in Riga showed rather a similar trend of paracetamol use in children with our present study. It was noted that half of the respondents $(50.1 \%)$ gave antipyretics to their children at a body temperature of $38.0^{\circ} \mathrm{C}$. Meanwhile, $33.1 \%$ of parents gave the medication when the children's body temperature was at $38.5^{\circ} \mathrm{C}$ (Urbane et al., 2019). However, a previous Italian study revealed that $71.6 \%$ of parents treat their children with paracetamol at a temperature between $38.0^{\circ} \mathrm{C}$ and $38.4^{\circ} \mathrm{C}$, while $21.0 \%$ of parents gave paracetamol for body temperature under $38.0^{\circ} \mathrm{C}$ (Lubrano et al., 2016).

The trend based on this study showed that higher age groups use tablet paracetamol formulation more than the lower age groups. There was also a difference between the age groups of the children and the formulations used. It concurred with existing research in Nigeria (Obu et al., 2012). The study showed that near to $40.0 \%$ of parents used syrup formulation for children under 5 years old, while more than half of parents $(59.5 \%$ and $52.2 \%)$ used tablet paracetamol for children aged 5 to 10 years and 11 to 16 years, respectively (Obu et al., 2012). A similar trend of formulations used with the age of children was observed between the Nigerian study and our present study. This could be due to the wide availability of paracetamol strength. The tablet paracetamol has a higher strength as compared to the syrup formulation. Older children need higher doses of paracetamol; hence, taking the tablet formulation will be more convenient than taking a large amount of paracetamol syrup. 
Table 4. Assessment on the appropriateness of the dose, frequency and total daily dose given by the parents to the children.

\begin{tabular}{|c|c|c|c|c|c|c|c|c|c|c|c|c|}
\hline \multirow{2}{*}{$\begin{array}{c}\text { Types of } \\
\text { formulation }\end{array}$} & \multirow{2}{*}{$\begin{array}{l}\text { Age } \\
\text { (year) }\end{array}$} & \multicolumn{2}{|c|}{$\begin{array}{c}\text { User } \\
N(\%)\end{array}$} & \multicolumn{3}{|c|}{$\begin{array}{l}\text { Dose }^{\mathrm{a}} \\
N(\%)\end{array}$} & \multicolumn{3}{|c|}{$\begin{array}{c}\text { Frequency }^{\mathrm{a}} \\
\qquad N(\%)\end{array}$} & \multicolumn{3}{|c|}{$\begin{array}{l}\text { Total daily dose } \mathrm{e}^{\mathrm{a}} \\
\qquad N(\%)\end{array}$} \\
\hline & & Yes & No & $A$ & $O$ & $U$ & $A$ & $O$ & $U$ & $A$ & $O$ & $U$ \\
\hline \multirow[t]{8}{*}{ Syrup } & $1-3$ & 31 & 9 & 3 & 9 & 12 & $19(61.3)$ & 12 & 0 & 7 & 9 & 8 \\
\hline & & $(77.5)$ & $(22.5)$ & (12.5) & $(37.5)$ & $(50.0)$ & & $(38.7)$ & $(0.0)$ & $(29.2)$ & $(37.5)$ & (33.3) \\
\hline & $4-6$ & 41 & 5 & 18 & 1 & 12 & 25 & 15 & 1 & 16 & 6 & 9 \\
\hline & & $(89.1)$ & (10.9) & $(58.1)$ & $(3.2)$ & $(38.7)$ & $(61.0)$ & $(36.6)$ & (2.4) & $(51.6)$ & (19.4) & (29.0) \\
\hline & $7-9$ & 40 & 4 & 5 & 0 & 18 & 19 & 20 & 1 & 9 & 2 & 12 \\
\hline & & (90.9) & $(9.1)$ & $(21.7)$ & $(0.0)$ & $(78.3)$ & $(47.5)$ & $(50.0)$ & $(2.5)$ & $(39.1)$ & (8.7) & (52.2) \\
\hline & $10-12$ & 23 & 10 & 4 & 0 & 13 & 11 & 11 & 1 & 6 & 0 & 11 \\
\hline & & $(69.7)$ & $(30.3)$ & $(23.5)$ & $(0.0)$ & $(76.5)$ & $(47.8)$ & $(47.8)$ & $(4.4)$ & $(35.3)$ & $(0.0)$ & (64.7) \\
\hline \multirow[t]{6}{*}{ Tablet } & $4-6$ & 5 & 41 & 0 & 2 & 2 & 2 & 3 & 0 & 2 & 0 & 2 \\
\hline & & (10.9) & $(89.1)$ & $(0.0)$ & $(50.0)$ & $(50.0)$ & $(40.0)$ & $(60.0)$ & $(0.0)$ & $(50.0)$ & $(0.0)$ & (50.0) \\
\hline & $7-9$ & 12 & 32 & 0 & 7 & 0 & 4 & 7 & 1 & 4 & 0 & 3 \\
\hline & & $(27.3)$ & $(72.7)$ & $(0.0)$ & $(100.0)$ & $(0.0)$ & $(33.3)$ & $(58.3)$ & (8.3) & $(57.1)$ & $(0.0)$ & (42.9) \\
\hline & $10-12$ & 20 & 13 & 4 & 0 & 11 & 12 & 7 & 1 & 9 & 0 & 6 \\
\hline & & $(60.6)$ & (39.4) & $(26.7)$ & $(0.0)$ & (73.3) & $(60.0)$ & $(35.0)$ & (5.0) & $(60.0)$ & $(0.0)$ & (40.0) \\
\hline
\end{tabular}

${ }^{\mathrm{a}}$ Assessment was done only to those parents who know the paracetamol strengths.

Notes: $A=$ appropriate; $O=$ overdose; $U=$ underdose.

There are numerous reasons for the increasing trend of paracetamol use in children. The most common cause is the easy access to OTC drugs in most countries. Parents are more motivated to treat their children with paracetamol as they believed that paracetamol improves the well-being of feverish children. Studies revealed that parents believe that the general well-being of their children is improved by paracetamol, allowing them to become more alert, have increased appetite, and fall asleep more easily (de Bont et al., 2020). It has been internationally reported that paracetamol can produce a good result and be a convenient practice for children. Besides, self-medication at home has become a common practice increasing among parents (Jain et al., 2011). In the present study, most parents will keep paracetamol at home. This finding concurred with research conducted among Malaysian consumers (Chong et al., 2017). Thus, having paracetamol kept at home can conveniently promote self-medication that contributes to the rising trend of paracetamol use among parents for their children.

Most parents do not hesitate to use antipyretics in treating the fever in their children prior to admission to the pediatric emergency department. A qualitative approach was conducted to interview caregivers to assess their misconceptions about fever in children. The results revealed that the parents perceived fever as a serious problem in children and they felt relief once the fever was resolved (Villarejo-Rodríguez and Rodríguez-Martín, 2019). Another study revealed that almost half of the parents $(45.0 \%)$ decided on their own to administer paracetamol to their children. Most of them (71.2\%) relied on experiences to decide the dose to be administered and only 13 parents $(8.3 \%)$ gave the appropriate dosage/day (Obu et al., 2012). This is a worrying practice for parents to use paracetamol in treating their children especially when they do not follow the advice, modify the treatment under the lack of knowledge, and are unaware of potential risk. Our present study found that a few parents doubled the paracetamol dose or gave it more frequently if their children's fever persisted. The present study also postulated a similar result conducted in Penang that consumers managed their persistent fever also by doubling the dose or taking it more frequently (Chong et al., 2017). This is a concerning practice as inaccurate doses of paracetamol might be served. Besides, a previous study reported that about a quarter $(25 \%)$ of parents gave paracetamol doses exceeding the permitted weight of the children (Nithisha and Sharma, 2018). It was noted in the study that the dosage per day of paracetamol was significantly more in parents who were practicing self-medication. Most of the respondents (60\%) who gave incorrect doses were self-medicated. Meanwhile, near to $90 \%$ of parents who gave inaccurate paracetamol doses felt it was harmless to self-administer and advised others to self-medicate as well (Nithisha and Sharma, 2018). Improper self-medication might possess a risk to staggered doses of paracetamol ingestion, leading to paracetamol poisoning. Hence, the parents should be educated on the appropriate dose and dosing frequency of paracetamol to be used in their children.

In our study, although $82.7 \%$ of parents revealed that they received medical advice when purchasing paracetamol, the medical advice received in terms of dosage, frequency, indication, precautions, and side effects with regard to paracetamol was less than $30 \%$. This may cause inappropriate practices among parents to treat their children with paracetamol. A qualitative study showed that parents have increased anxiety when their concerns about their children's fever were not recognized (Van De Maat et al., 2018). Some parents had the experience that they were not taken seriously especially with their complaints not fully addressed by the healthcare providers (Van De Maat et al., 2018). In our study, the majority of respondents received medical advice on paracetamol from doctors and pharmacists. A study showed that information given by general practitioners (GPs) influenced 
Table 5. Assessment on the total daily dose given by the parents to the children (syrup and tablet).

\begin{tabular}{|c|c|c|c|c|c|c|c|c|}
\hline \multirow[b]{2}{*}{$\begin{array}{c}\text { Types of } \\
\text { formulation }\end{array}$} & \multirow[b]{2}{*}{ Age } & \multirow[b]{2}{*}{$\begin{array}{l}\text { Recommended total } \\
\text { daily dose }\end{array}$} & \multicolumn{2}{|c|}{ Under dose } & \multicolumn{2}{|c|}{ Overdose } & \multicolumn{2}{|c|}{ Overall total daily dose } \\
\hline & & & $\begin{array}{c}N \\
(\%)\end{array}$ & $\begin{array}{c}{ }^{\text {a } M e d i a n ~ d o s e ~} \\
\text { (IQR) } \\
\text { (mg) }\end{array}$ & $N(\%)$ & $\begin{array}{c}{ }^{\text {a Median dose }} \\
\text { (IQR) } \\
\text { (mg) }\end{array}$ & $N(\%)$ & $\begin{array}{c}{ }^{\text {a}} \text { Median dose } \\
\text { (IQR) } \\
\text { (mg) }\end{array}$ \\
\hline \multirow[t]{8}{*}{ Syrup } & $1-3$ & $432-960 \mathrm{mg}$ & 8 & 80 & 9 & 72 & 24 & 625 \\
\hline & & & $(20.0)$ & $(40-520)$ & $(52.9)$ & $(72-192)$ & $(25.2)$ & $(360-1,000)$ \\
\hline & $4-6$ & $720-1,440 \mathrm{mg}$ & 9 & 240 & 6 & $60^{\mathrm{b}}$ & 31 & 1,000 \\
\hline & & & $(22.5)$ & $(240-490)$ & $(35.3)$ & & $(32.6)$ & $(660-1,080)$ \\
\hline & $7-9$ & $1,050-2,000 \mathrm{mg}$ & 12 & 330 & 2 & 625 & 23 & 750 \\
\hline & & & $(30.0)$ & $(300-570)$ & (11.8) & $(250-1,000)$ & $(24.2)$ & $(720-1,500)$ \\
\hline & $10-12$ & $1,500-3,000 \mathrm{mg}$ & 11 & 500 & 0 & - & 17 & 750 \\
\hline & & & $(27.5)$ & $(330-750)$ & $(0.0)$ & & $(17.9)$ & $(720-1,500)$ \\
\hline \multirow[t]{6}{*}{ Tablet } & $4-6$ & $720-1,440 \mathrm{mg}$ & 2 & 285 & 0 & - & 4 & 1,000 \\
\hline & & & $(18.2)$ & $(240-330)$ & $(0.0)$ & & $(15.4)$ & $(660-1,080)$ \\
\hline & $7-9$ & $1,050-2,000 \mathrm{mg}$ & 3 & 300 & 0 & - & 7 & 750 \\
\hline & & & $(27.3)$ & $(50-315)$ & $(0.0)$ & & (26.9) & $(720-1,500)$ \\
\hline & $10-12$ & $1,500-3,000 \mathrm{mg}$ & 6 & 500 & 0 & - & 15 & 1,500 \\
\hline & & & $(54.5)$ & $(500-817.5)$ & $(0.0)$ & & (57.7) & $(1,000-1,625)$ \\
\hline
\end{tabular}

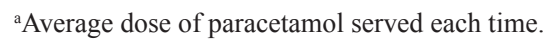

${ }^{\mathrm{b}}$ All the six parents give overdose of $60 \mathrm{mg}$.

parents' paracetamol use (Jensen et al., 2010). A study showed that more than $90 \%$ of the parents sought their GPs for advice to treat their children's fever (Jensen et al., 2010). Hence, doctors and pharmacists play a crucial role in providing adequate information to the parents.

Our present study revealed that underdosing (dose per intake) of paracetamol syrup formulation in children was more prominent in the higher age groups 7-9 years and 10-12 years, respectively. This study's findings of inaccurate doses were quite consistent with a study in Sri Lanka that suggested that the risk of receiving an incorrect dose increased with increasing age. The majority of children (77\%) aged above 3 years, while only $32 \%$ of children of age 3 years and below were given inaccurate doses of paracetamol, respectively (Ramanayake et al., 2012). More than half of parents $(54 \%)$ gave inaccurate paracetamol doses to their children with $11 \%$ being subrecommended doses $(<10 \mathrm{mg} /$ $\mathrm{kg} /$ dose) and $43 \%$ being supratherapeutic doses ( $>15 \mathrm{mg} / \mathrm{kg} / \mathrm{dose})$ (Ramanayake et al., 2012). Research in India also reported that only $8.3 \%$ of parents served appropriate doses of paracetamol to the children based on weight with $66.7 \%$ of children being administered with doses below the recommended dosage $(60 \mathrm{mg}$ / $\mathrm{kg}$ /day) (Nithisha and Sharma, 2018). Therefore, this problem needs to be addressed as the inappropriate dosing of paracetamol will lead to ineffective treatment.

A trend of paracetamol overdose by the parents in treating their children was observed in this study. Hence, healthcare providers should be alert about the dose given by the parents to their children. Paracetamol overdose is particularly dangerous as it may cause hepatic damage which is sometimes not apparent for 4 to 6 days (British Medical Association and Royal Pharmaceutical
Society of Great Britain, 2011). As found in our present study, it is observed that some parents gave their children syrup or tablet paracetamol overfrequently. This can potentially contribute to the risk of staggered paracetamol overdose. Many reported cases of severe hepatotoxicity in children have been attributed to cumulative toxicity from repeated doses rather than acute intoxication from a single massive overdose (Kanabar, 2017; Nithisha and Sharma, 2018). Poor knowledge regarding side effects, toxic dose, and wide accessibility of paracetamol are among the factors contributing to the irrational usage of the paracetamol among parents. Although paracetamol generally is regarded as a very safe antipyretic drug, liver failure is a well-recognized consequence of paracetamol overdose (Kamatchi et al., 2012). Parents still believe that they have good knowledge and would advise others to self-medicate their children with paracetamol although they were administering the incorrect dosage (Nithisha and Sharma, 2018). Hence, proper education with regard to paracetamol use should be provided to parents to cope with this issue of giving an inaccurate dose of paracetamol to their children.

\section{LIMITATIONS}

Limited generalizability is one of the limitations as the findings cannot represent the practices of paracetamol uses among parents to treat their children at places other than Penang. Besides, this study did not evaluate the cause and effect relationship of the gender, age, education background, and income among parents with their practice of paracetamol uses. The correlation is important to determine whether the cause and effect are significant to allow more interventions targeting the specific group of parents' demographics. In addition, the use of convenient sampling in the study might lead to selection bias. A nationwide study involving 
multicentered and random sampling would overcome the limitation of the present study.

\section{CONCLUSION}

Paracetamol is a very common medicine used by parents to treat fever in children. However, it was found that parents are giving inaccurate doses of paracetamol to their children. This issue needs to be addressed as inaccurate paracetamol dosing can lead to paracetamol poisoning or ineffective treatment for children. Several future perspectives should be considered to improve the current research and practice. Research should be conducted to design a specific formula to calculate the exact dose of paracetamol based on the children's body weight, age, and gender. The formula can aid in reducing the dose calculation error by healthcare providers and parents. As there is no current local guideline, this study findings can guide the design of a publicly accessible guideline on paracetamol use in children. Ideas to sensitive the population involved in the use of paracetamol considering the dosage, age, and gender should be implemented. A detailed local guideline should explain the paracetamol dosage according to children's body weight, age, and gender. The guideline should also help the parents to understand the product labeling of the paracetamol syrups available in the market. Furthermore, infographics showing the appropriate dose of paracetamol and the potential side effects of paracetamol poisoning can be designed to educate parents on the safe use of paracetamol in their children. The infographics should also keep parents aware of the available brands, strengths of paracetamol syrups in the market, and the appropriate dosage based on age and gender. These infographics can be disseminated through visits to pharmacies or the websites of the Ministry of Health Malaysia.

\section{ACKNOWLEDGEMENT}

The authors would like to thank all the study respondents.

\section{AUTHOR CONTRIBUTIONS}

All authors made substantial contributions to conception and design, acquisition of data, or analysis and interpretation of data; took part in drafting the article or revising it critically for important intellectual content; agreed to submit to the current journal; gave final approval of the version to be published; and agree to be accountable for all aspects of the work. All the authors are eligible to be an author as per the international committee of medical journal editors (ICMJE) requirements/guidelines.

\section{FUNDING}

There is no funding to report.

\section{CONFLICTS OF INTEREST}

The authors report no financial or any other conflicts of interest in this work.

\section{PUBLISHER'S NOTE}

This journal remains neutral with regard to jurisdictional claims in published institutional affiliation.

\section{REFERENCES}

Almasdy D, Sharrif A. Self-medication practice with nonprescription medication among university students: a review of the literature. Arch Pharm Pract, 2011; 2(3):95-100.
British Medical Association, Royal Pharmaceutical Society of Great Britain. British National Formulary No. 62, September 2011. British Medical Association and Royal Pharmaceutical Society of Great Britain, London, UK, 2011.

Bennett S. Pharmacology of paracetamol and prescribing considerations. Nurse Prescribing, 2013; 11(1):28-33.

Cairns R, Brown JA, Wylie CE, Dawson AH, Isbister GK, Buckley NA. Paracetamol poisoning-related hospital admissions and deaths in Australia, 2004-2017. Med J Aust, 2019; 211(5):218-23.

Chiew AL, Gluud C, Brok J, Buckley NA. Interventions for paracetamol (acetaminophen) overdose. Cochrane Database Syst Rev, 2018; 2(2):CD003328

Chong CP, Tan SF, Chooi WT. An evaluation on consumers' usage pattern of acetaminophen (paracetamol): a multicenter study from Penang, Malaysia. Arch Pharm Pract, 2017; 8(1):15-21.

Choudhury P, Bagga A, Chugh K, Ramji S. Principles of pediatric and neonatal emergencies. Jaypee Brothers Medical Publishers (P) Ltd, New Delhi, India, 2011.

Craig DGN, Bates CM, Davidson JS, Martin KG, Hayes PC, Simpson KJ. Staggered overdose pattern and delay to hospital presentation are associated with adverse outcomes following paracetamol-induced hepatotoxicity. Br J Clin Pharmacol, 2012; 73(2):285-94.

Daifallah A, Jabr R, Al-Tawil F, Elkourdi M, Salman Z, Koni A, Samara A, Al-Jabi SW, Zyoud SH. An assessment of parents' knowledge and awareness regarding paracetamol use in children: a cross-sectional study from Palestine. BMC Public Health, 2021; 21(1):380.

de Bont EGPM, Bohnen JMHA, Verhoeven R, Dinant GJ, Cals JWL. Childhood fever: parental paracetamol administration after consulting out-of-hours general practice. Eur J Gen Pract, 2020; 26(1):21-5.

Eyers S, Fingleton J, Eastwood A, Perrin K, Beasley R. British National Formulary for Children: the risk of inappropriate paracetamol prescribing. Arch Dis Child, 2012; 97(3):279-82.

Gunduz S, Usak E, Koksal T, Canbal M. Why fever phobia is still common? Iran Red Crescent Med J, 2016; 18(8):e23827.

Jain S, Malvi R, Purviya JK. Concept of self medication: a review. Int J Pharm Biol Arch, 2011; 2(3):831-6.

Jensen JF, Tønnesen LL, Söderström M, Thorsen H, Siersma V. Paracetamol for feverish children: parental motives and experiences. Scand J Prim Health Care, 2010; 28(2):115-20.

Kamatchi R, Bandyopadhyay S, Jainer AK, Somashekar B, Marzanski M, Marwaha S. 3 years on: examiners' and candidates' views on the CASC (Clinical Assessment of Skills and Competencies). Br J Med Pract, 2012; 5(4):a537.

Kanabar DJ. A clinical and safety review of paracetamol and ibuprofen in children. Inflammopharmacology, 2017; 25(1):1-9.

Lenney W. Paracetamol prescription by age or by weight? Arch Dis Child, 2012; 97:277-8.

Lubrano R, Paoli S, Bonci M, Di Ruzza L, Cecchetti C, Falsaperla R, Pavone P, Matin N, Vitaliti G, Gentile I. Acetaminophen administration in pediatric age: an observational prospective cross-sectional study. Ital J Pediatr, 2016; 42(1):20.

Lundgren M, Steed LJ, Tamura R, Jonsdottir B, Gesualdo P, Crouch C, Sjöberg M, Hansson G, Hagopian WA, Ziegler AG, Rewers MJ. Analgesic antipyretic use among young children in the TEDDY study: no association with islet autoimmunity. BMC Pediatr, 2017; 17:127.

Martino M, Chiarugi A. Recent advances in pediatric use of oral paracetamol in fever and pain management. Pain Ther, 2015; 2(4):149-68.

Nithisha T, Sharma SK. Extent and pattern of paracetamol usage for children and knowledge and attitude towards its usage among parents attending an outpatient clinic in Warangal district of Telangana. In J Community Med Public Health, 2018; 5(6):2394-9.

Obu HA, Chinawa JM, Ubesie AC, Eke CB, Ndu IK. Paracetamol use (and/or misuse) in children in Enugu, South-East, Nigeria BMC Pediatr, 2012; 12(1):103.

Ramanayake RPJC, Jayasinghe LR, De Silva AHW, Wijesinghe WATA, Kanaganayagam N. Knowledge and practices of paracetamol 
administration among caregivers of pediatric age group patients. J Family Med Prim Care, 2012; 1(1):30-3.

Shone LP, King JP, Doane C, Wilson KM, Wolf MS. Misunderstanding and potential unintended misuse of acetaminophen among adolescents and young adults. J Health Commun, 2011; 16(Suppl 3):256-67.

Tesfamariam S, Anand IS, Kaleab G, Berhane S, Woldai B, Habte E, Russom M. Self-medication with over the counter drugs, prevalence of risky practice and its associated factors in pharmacy outlets of Asmara, Eritrea. BMC Public Health, 2019; 19:159.

Urbane UN, Likopa Z, Gardovska D, Pavare J. Beliefs, practices and health care seeking behavior of parents regarding fever in children. Medicina, 2019; 55(7):398.

Van De Maat JS, Van Klink D, den Hartogh-Griffioen A, Schmidt-Cnossen E, Rippen H, Hoek A, Neill S, Lakhanpaul M, Moll HA, Oostenbrink R. Development and evaluation of a hospital discharge information package to empower parents in caring for a child with a fever. BMJ Open, 2018; 8(8):e021697.

Villarejo-Rodríguez MG, Rodríguez-Martín B. A qualitative study of parents' conceptualizations on fever in children aged 0 to 12 years. Int J Environ Res Public Health, 2019; 16(16):2959.

\section{How to cite this article:}

Yeoh ET, Goh AWL, Chong CP. Evaluation of the practices of using paracetamol among parents in treating their children in Penang, Malaysia. J Appl Pharm Sci, 2022; 12(01):120-130. 